\title{
Runaway Social Selection for Displays of Partner Value and Altruism
}

\section{Randolph M. Nesse}

Departments of Psychiatry, Psychology, and Research Center for Group Dynamics at the Institute for Social Research

University of Michigan

Ann Arbor, MI, USA

nesse@umich.edu

\begin{abstract}
Runaway social selection resulting from partner choice may have shaped aspects of human cooperation and complex sociality that are otherwise hard to account for. Social selection is the subtype of natural selection that results from the social behaviors of other individuals. Competition to be chosen as a social partner can, like competition to be chosen as a mate, result in runaway selection that shapes extreme traits. People prefer partners who display valuable resources and bestow them selectively on close partners. The resulting phenotypic covariance between displays and preferences gives fitness advantages to both, creating runaway selection that could shape a whole suite of prosocial traits including altruism, moral capacities, empathy, and theory of mind. Even though they give a net fitness benefit, traits at the endpoint of runaway social selection can have substantial deleterious effects on other traits such as viability, ability to accumulate resources, or vulnerability to mental disorders. Social selection forces arising from self-interested partner choices may be an invisible hand that shaped capacities for commitment, altruism, and other prosocial capacities of the human social brain.
\end{abstract}

\section{Keywords}

altruism, commitment, cooperation, evolution, morality, partner choice, relationships, runaway social selection 
The discovery of evolutionary explanations for cooperation is one of the great achievements of late 20th-century biology. As most readers know, benefits to the group rarely explain tendencies to help others (Williams 1966; Dawkins 1976), benefits to kin explain altruism in proportion to the coefficient of relatedness (Hamilton 1964), and mutual benefits and reciprocal exchanges explain much cooperation between nonrelatives (Trivers 1971). Subsequent theoretical and empirical studies have blossomed into a body of knowledge that can explain much social behavior (Wilson 1975; Trivers 1985; Dugatkin 1997; Alcock 2001; Hammerstein 2003).

Controversies continue, however. Some arise from a profusion of models for cooperation that use inconsistent terminology and tend to emphasize one explanation when several may apply (Frank 1998; Hirshleifer 1999; Hammerstein 2003; Lehmann and Keller 2006; Nowak 2006; West et al. 2007). Other controversies reflect impassioned debates about human nature (Midgley 1994; Wright 1994; Ridley 1997; Segerstråle 2000; de Waal et al. 2006; Dugatkin 2006). However, some controversies persist because no explanation seems entirely satisfactory for some phenomena, especially human capacities for altruism and complex sociality.

While kin selection and variations on reciprocity explain most human capacities for cooperation, some observations don't fit the usual models. In behavioral economics laboratory experiments and in everyday life, people tend to be more altruistic than predicted (Gintis 2000; Fehr and Rockenbach 2004; Brown and Brown 2006; de Waal et al. 2006). They also tend to punish defectors even when that is costly (Henrich and Boyd 2001; Boyd et al. 2003). People follow rules and they are preoccupied with morals and mores, monitoring and gossiping about even minor deviations (Axelrod 1986; Katz 2000; Krebs 2000; de Waal et al. 2006). Perhaps most interesting of all, close friends take pains to avoid making exchanges explicit because calling attention to them harms relationships (Batson 1991; Mills and Clark 1994; Dunbar 1996; Tooby and Cosmides 1996; Nesse 2001, 2006; Brown and Brown 2006). Friendships exist, but they remain in want of a satisfactory evolutionary explanation (Smuts 1985; Silk 2003).

This article argues that well-established models of social selection may explain how partner choice could shape extreme prosocial traits in humans. It begins by reviewing early descriptions of social selection (West-Eberhard 1979, 1983) and more recent formal models that illustrate the value of calculating the fitness components from social selection separately from those that arise from the rest of natural selection (Tanaka 1996; Frank 1998, 2006; Wolf et al. 1999). Next, it reviews the recent recognition of the power of partner choice (Noë and Hammerstein 1994) and connects these insights with recent models of how covariance of partner phenotypes can lead to runaway social selection (Tanaka 1996; Breden and Wade 1991). These lines of work come together with recent work on human altruism to suggest that the fitness benefits of being chosen as a partner may shape extreme displays of partner value, including capacities for genuine altruism, that are otherwise difficult to explain.

\section{Social Selection}

Social selection is the subtype of natural selection in which fitness is influenced by the behavior of other individuals (WestEberhard 1979, 1983; Wolf et al. 1999; Frank 2006). Although well established in biology, the term social selection is slightly problematic because epidemiologists use the same phrase to describe the entirely different phenomenon of some social groups having a higher proportion of individuals with some condition. For instance, the proportion of people with schizophrenia is higher in inner cities simply because many cannot afford to live elsewhere. Also potentially confusing is the idiosyncratic use of social selection as an alternative to sexual selection (Roughgarden et al. 2006), when in fact it is a subtype. These potential confusions aside, social selection is the standard term for fitness changes resulting from the social behaviors of other individuals.

Sexual selection by female choice is the best-known subtype of social selection. Female biases for mating with ornamented males select for more elaborate male displays, and the advantages of having sons with extreme displays (and perhaps advantages from getting good genes) select for stronger preferences (Grafen 1990; Kokko et al. 2003). The resulting positive feedback makes displays and preferences more and more extreme until genetic variation is exhausted, or until the fitness increase from more matings equals the fitness decrease from lowered competitive ability and earlier mortality (Andersson 1994; Kokko et al. 2006). Sexual selection is social selection because individual fitness is influenced by the choices and behaviors of other individuals. West-Eberhard made the point succinctly it in one of the first papers on the topic:

Sexual selection refers to the subset of social competition in which the resource at stake is mates. And social selection is differential reproductive success (ultimately, differential gene replication) due to differential success in social competition, whatever the resource at stake. (1979: 158).

Social selection arising from conspecific choices and behaviors has been described in detail (Crook 1972; West-Eberhard 1975; West-Eberhard 1983; Tanaka 1996; Wolf et al. 1999; Frank 2006). Suprisingly, however, its full power is only now being recognized. The perspective of social selection shifts attention away from individual strategies in iterated exchanges, and toward the prior and larger fitness challenges of identifying the best available partners and doing whatever will get them to choose one as a partner. In formal models, this means partitioning the force of social selection resulting from the covariance 
of partners' phenotypes separately from other forces of natural selection. Following Queller (1992) and Frank (1997), Wolf et al. (1999) describe social selection by saying "factors other than one's own phenotype may affect an individual's fitness... individual variation in fitness can be attributed to variation in the value of traits expressed by an individual's social partners." (1999: 255-256).

Building from Lande and Arnold's model of sexual selection (1983), Wolf. et al. (1999: 256) partition relative fitness $\omega$ into one component from social selection and a separate component from the rest of natural selection: $\omega=$ $\alpha+\beta_{\mathrm{N}} \mathrm{Z}_{\mathrm{i}}+\beta_{\mathrm{S}} \mathrm{z}_{\mathrm{j}}^{\prime}+\varepsilon$, where $\beta_{\mathrm{N}}$ is the natural selection gradient, $\beta_{\mathrm{S}}$ is the social selection gradient, $\mathrm{z}_{\mathrm{i}}$ is the trait in the individual and $z_{\mathrm{j}}^{\prime}$ is a covarying trait in the partner (the prime sign indicates that the trait is in the partner, $\alpha$ is fitness uncorrelated with the traits, and $\varepsilon$ is error). They then derive a generalized phenotypic version of Hamilton's rule to show that selection favors an altruistic trait $\mathrm{z}_{\mathrm{ij}}$ whenever $\frac{C^{\mathrm{ij}}}{P_{\mathrm{ii}}} \beta_{\mathrm{S}}+\beta_{\mathrm{N}}>0$, where $C^{\mathrm{ij}}$ is the phenotypic covariance between the trait in the individual and the partner, and $P_{\mathrm{ii}}$ is the character's variance. Here, $\beta_{\mathrm{N}}$ is the selection cost for an altruistic trait (and will therefore be $<0$ ), and $\beta_{\mathrm{S}}$ is the benefit to the partner (which will be $>0$ ), so the altruistic trait will be selected only if its covariance with the associated trait is large compared to the trait's variance. The model, very similar to Frank's (1997, 1998) and also drawing on Fisher and Price, is based on phenotypes and does not require covariance of genes within individuals. Partner choice creates phenotypic covariance that can shape extreme traits such as displays of one's value as a partner. How far will social selection push such traits at the expense of other components of natural selection? An answer to this important question requires detailed analysis of social selection by partner choice.

While all social behavioral tendencies can be interpreted as products of social selection because they involve choice by other individuals (Wolf et al. 1999; Frank 2006), the emphasis here is on forces of selection that arise from choices about relationship partners and group membership. If potential partners or group members vary in resources and tendencies to reliably bestow them on close partners, then a preference for resource-rich, selectively altruistic partners will give a selective advantage. Being preferred as a partner gives fitness advantages because it gives more possible partners to choose from (Noë and Hammerstein 1994). This will select for displays of resources and selective altruism that reflect an individual's potential value as a partner.

The nonrandom association of individuals with extreme displays and those with strong preferences can result in runaway social selection increasing both traits to extremes that decrease other fitness parameters (Breden and Wade 1991; Tanaka 1996; Wolf et al. 1999). This model differs from sexual selection because in most cases preferences and dis- plays will both be present in the same individuals. Also, benefits to others pay off not only directly, but also because benefits to partners eventually result in benefits to the self via interdependence (Rothstein 1980; Humphrey 1997; Brown and Brown 2006). At equilibrium, many individuals will be presenting and assessing expensive displays in a competition that results in partnerships between individuals of similar partner value.

In sexual selection, runaway occurs only when the covariance of the trait and the display is greater than the viability decrease from the display. At equilibrium, further increases in female preference would lower fitness because of decreased viability of sons (Kokko et al. 2006). However, "even small changes in female behavior (which cost little) can generate strong selection when a male's fitness depends primarily on his mating success" (Kokko et al. 2006: 59). In selection for social partners, the cost of choosing partners with extremely high value has little or no disadvantage comparable to the disadvantage experienced by females who choose mates with the most extreme displays. Displays of partner value will, therefore, continue under directional selection until their marginal benefits impose equal costs to other fitness components, such as ability to accumulate material resources. Thus, social selection for partners can, like sexual selection, explain extremely costly traits.

In a model of social selection that emphasizes signaling submission and real fighting ability, Tanaka (1996) addresses the possibility of runaway social selection more directly. As in the Wolf et al. model, fitness is partitioned into components from social selection that are distinct from the rest of natural selection in order to assess where the equilibrium for a signal lies. That point often is reached, he concludes, by runaway selection that quickly arrives at the equilibrium where the marginal benefits of further increasing the signal are balanced by its direct costs. Crespi (2004) has argued that such positive feedback cycles are much more common in nature than is usually recognized. Deception and cheating have been major themes in reciprocity research, and they apply in social selection models, but their effects are limited by inexpensive gossip about reputations and by the difficulty of faking expensive resource displays (Tanaka 1996).

\section{Social Selection in Nature}

If the above models are correct, then examples of nonsexual social selection should be observed in the natural world. Some examples of traits shaped by preferences in one species for displays in another species illustrate runaway selection without genetic covariation in the same genome. As Darwin noted (1871), flowers have elaborate and diverse forms because they compete to satisfy pollinator preferences. Flowers preferred by pollinators contribute more genes to future generations, 
so floral displays become increasingly extravagant until the marginal benefits from attracting more pollinators are matched by costs to other aspects of fitness, such as investment in leaves and roots (Armbruster et al. 2005). Benefits can also come from not being chosen. Staying near the center of a selfish herd is shaped by predator preferences. Stotting protects gazelles because it is an honest signal of vigor that discourages predators from useless chases.

Signals between members of the same species are shaped by the same mechanisms (Grafen 1984; Bradbury and Vehrencamp 1998). Social coordination signals are ubiquitous. For instance, a bird on a nest makes distinctive movements to signal to its partner that it is ready to trade roles. The signal benefits both parties, so there is no selection for an extreme signal. In competitive situations, amplified signals are common (Takana 1996). When a wolf bares its throat to signal yielding in a fight, both parties benefit by avoiding the danger of an escalated fight; a prominent submission display that creates real vulnerability pays off by avoiding useless fighting. Status displays in lieu a fight are likely to be extreme because only expensive honest signals will influence the competitor. Note that such signaling behaviors give benefits only because they interact with the phenotypes of other individuals who have been primed by selection to be influenced.

Some examples, such as males competing for a territory, blur the boundary between sexual and other social selection. Others arise more clearly from nonsexual social selection, such as the huge brightly colored beaks of both male and female toucans. They do not result from sexual selection; nonsocial toucan species have less exaggerated and more sexually dimorphic beaks. They are more likely honest signals of ability to defend a nesting territory (West-Eberhard 1983). Bright coloration in both sexes is also prominent in territorial lizards and some mammals, especially lemurs. Social selection has also been proposed as the explanation for bright coloration of reef fish. West-Eberhard offers a wealth of examples, and reasons why species recognition hypotheses are insufficient (1983). She also notes that Wynne-Edwards (1962) provides additional examples, even if he was wrong about how selection shaped them. This is especially important because it highlights the power of social selection to account for phenomena that might otherwise appear to be products of group selection. While the sources of female ornamentation remain an active research focus, a recent review endorses the importance of social selection:

Almost 20 years ago, West-Eberhard argued that monomorphic showy plumage was associated with aggressive social displays (over territories or other resources) by both sexes. Her argument was supported by examples from several taxa including toucans, parrots and humming birds. West-Eberhard's suggestions resulted in surprisingly little empirical research in the following years. However, among published studies, most seem to support her view. (Amundsen 2000: 151)

\section{Domestication}

Domestication illustrates how social preferences can shape profoundly prosocial traits. It requires no conscious breeding, only preferences that influence fitness among individuals from the other species who vary on traits that matter to humans (Price 1984; Diamond 2002). For instance, wolves with less fear of humans and lower levels of aggression were able to, and allowed to, stay closer to ancestral human camps where the fitness value of food scraps was a domesticating selection force. In turn, those humans who had tendencies to be altruistic toward dog-progenitors received fitness benefits-initially warnings of danger, but later, help in the hunt and protection. This process selected for genes that increase human altruism toward dogs, and it shaped dogs who behave in ways that please humans enormously.

Humans also show many characteristics of being domesticated-low rates of aggression, increased cooperation, eagerness to please others, and even changes in bone structure similar to those characteristic of domesticated animals (Leach 2003). It seems plausible that humans have been domesticated by the preferences and choices of other humans. Individuals who please others get resources and help that increase fitness. Aggressive or selfish individuals get no such benefits and are at risk of exclusion from the group, with dire effects on fitness. The result is thoroughly domesticated humans, some of whom can be enormously pleasing.

This process does not depend on the success of the group. Instead, individuals constantly make small self-interested social choices that shape the behaviors of others who learn to do whatever works. The resulting effects on fitness shape the species by social selection. This process offers a dramatic example of a Baldwin effect, in which learning shapes adaptive behavior patterns that create new selection forces that rapidly facilitate better ability to exploit the new niche (Dennett 1995; Laland et al. 2000; Weber and Depew 2003; West-Eberhard 2003; Ananth 2005). Once the benefits of relationships increased above a crucial threshold, they created a newly complex social environment where individuals with special social skills got increasing fitness advantages shaped more extreme cognitive and prosocial traits (Humphrey 1976; Byrne and Whiten 1988; Alexander 2005).

Herbert Simon, in a 1990 article on "social selection and successful altruism," described how selection for "docility" could give rise to behaviors that benefit others more than the self. Simon defined docility as, "persons who are adept at social learning who accept well the instruction society provides them" (p. 1666). His model is based on the fitness benefits of general social learning, and the assumption that "limits on rationality in the face of environmental complexity" result in individuals behaving altruistically for the good of society without recognizing the "tax" they are paying. In contrast, the 
model developed in this article views altruism as a result of the fitness benefits of social selection, not as a result of cognitive constraints.

\section{Social Selection for Cooperation}

Indirect benefits to kin are one powerful force that shapes conspecific cooperation. Ability to recognize kin, and preferences for helping them, give benefits to genes in kin that are identical by descent to those in the helper (Hamilton 1964; Dugatkin 1997; Frank 1998; Queller and Strassmann 1998; West et al. 2002). This process has been described and studied so extensively that there is no need to repeat the details here. One subtype, "green-beard effects" has been controversial, but it now appears that selection does sometimes shape kinship cues that facilitate kin altruism (Queller et al. 2003). Phenotype variability can also be shaped by social interactions involved in reproductive competitions, at least in wasps (Tibbetts 2004).

Preferences for helping nonrelatives who will help in return are also obviously valuable (Trivers 1971). The challenge is how to get the benefits of trading favors without being exploited (Krebs and Dawkins 1984; Alexander 1987; Cosmides 1989; Fehr and Fischbacher 2003). Following Price (Frank 1997) and Queller (1992), Frank $(1997,2006)$ points out that such cooperation can be modeled as correlated behaviors, an information problem equivalent to that of kin selection. In kin selection, a behavior increases inclusive fitness if its cost to the self is less than the benefit to the other times the coefficient of relatedness, $r$. In correlated behaviors, the cost is the direct effects of the behavior on the individual's fitness, the benefit is the indirect benefit from others (holding constant individual behavior), and $r$ reflects the similarity of others' behavior, that is, the information an individual has about benefits others will likely offer. Both kin selection and correlated behavior can thus be analyzed by partitioning fitness into direct costs, indirect benefits, and a scaling factor that reflects relatedness in the former case, and information about other's anticipated behavior in the latter (Frank 1997; Wolf et al. 1999).

The iterated prisoner's dilemma has long been the dominant model for cooperation based on reciprocity (Axelrod 1984; Sigmund 1993; Axelrod 1997). In this model, the maximum joint benefit for two players comes from repeated cooperation, but an individual can get a greater payoff from defecting on any move when the other cooperates. Tit-For-Tat (starting with a cooperative act and then doing what the other person did on the previous move) is a remarkably robust strategy that nicely models some human interactions. The tractability of models based on the prisoner's dilemma has fostered scores of valuable studies (Axelrod 1997).

It is less clear, however, that prisoner's dilemma models accurately reflect the kinds of trait variation on which selection acted to create capacities for social cognition. In most studies, anonymous agents are randomly paired, information is only about prior behavior with one agent or the sum of all agents' behavior, the same algorithm is used for interactions with all other players, and only two outcomes are possible, cooperate or defect. Reputation and punishment have increasingly been added to such models (Fehr and Fischbacher 2003; Axelrod et al. 2004; Henrich et al. 2006). However, few reciprocity models have all of the ingredients that are important to human cooperation in close relationships: reputation, communication, agreements, promises, threats, third party enforcement, and especially, opportunities to use extensive information to choose partners from a selection of possibilities (Kitcher 1993; Hammerstein 2001; Nesse 2001; Noë 2001). While variations in tendencies to cooperate or defect in discrete interactions with rapidly shifting partners certainly create selection forces, they explain only some aspects of some human relationships (Fehr and Henrich 2003; Barclay and Willer 2007). Nonetheless, such models have been a boon for the study of cooperation.

Another difficulty is that the kinds of reciprocal exchange modeled by the prisoner's dilemma seem to be rare in nature. Most apparent examples of reciprocity identified by field research now appear to be better explained by kinship or mutual benefits (Connor 1995; Stevens et al. 2005). Cooperative hunting is a prime example. Participants all gain, so defection does not pay. Impala grooming is a reciprocal exchange, but of the most minimal kind. Grooming bouts are traded back and forth in parcels so small that the example blurs the border between reciprocity and mutualism (Connor 1995), although grooming may be tradable for other resources (Manson et al. 2004). Another example, previously thought to exemplify reciprocal exchange between nonrelatives, is vampire bats sharing blood with others who did not succeed in that night's hunt (Wilkinson 1984). However, it turns out the sharing almost always is between kin. Coalitions of male baboons were also thought to demonstrate reciprocity, but on reexamination, the males do not share mating opportunities to any great extent. A review by Stevens et al. (2005) assesses the evidence for reciprocity in nature and concludes that there are few examples, perhaps, they say, because most animals have severe capacity constraints for memory and cognition.

Where reciprocal helping does exist, it is usually maintained by systems for assessing potential partners or withdrawing resources from defectors (Sachs et al. 2004). Parceling, as in reciprocal grooming, distributes resources in small packets so defection is not an issue (Connor 1995). Another strategy is to distribute resources selectively depending on the behavior of others. For instance, yucca plants abandon flowers with too many moth larvae. This can be viewed as a punishment that selects for moths who limit egg deposition. However, abandoning the flowers with too many larvae is in the direct self-interest 
of the yucca plant, and this makes it advantageous for moths to limit the number of eggs laid in any one flower.

Image scoring (Nowak and Sigmund 1998; Wedekind and Milinski 2000) and other reputation-based strategies such as indirect reciprocity (Alexander 1987), offer information about an individual's reliability as a partner and can lead to mutually profitable exchanges even in the absence of repeated interactions (Riolo et al. 2001). This is not the place to analyze the diversity of cooperation models, but it is important to recognize that delayed reciprocal exchange of resources is as rare in other animals as it is ubiquitous in humans. Furthermore, human cultures vary substantially in their levels of individual cooperation, with much of the variance attributable to variations in the patterns of economic exchange (Henrich et al. 2005), further demonstrating that human cooperation strategies are marshaled to suit the circumstances.

The role of partner choice in facilitating cooperation has long been recognized (Bull and Rice 1991), but has been emphasized only recently (Noë and Hammerstein 1994; Noë 2001; Sachs et al. 2004). When there is choice, potential partners must compete in markets that change the dynamics of cooperation. Between-species partner choice is illustrated by symbioses in which the slower-evolving organism selects among individuals in a faster evolving species to get the most valuable partners, for instance, the plant symbioses with bacteria and fungi (Simms and Taylor 2002; Kummel and Salant 2006). Choice of conspecific partners may be far more powerful (Roberts 1998; Noë and Hammerstein 1994).

\section{Social Selection for Prosocial Traits in Humans}

The possibility that social selection shaped human capacities for altruism and complex sociality was suggested in WestEberhard's seminal publication on the topic (1979: 228):

It is tempting to speculate that the explosive evolutionary increase in the proto hominid brain size, which had the appearance of a "runaway" process, was associated with the advantage of intelligence in the maneuvering and plasticity associated with social competition in primates.

The complexity of the social environment is widely recognized as a selection force likely to be important for explaining human social abilities (Humphrey 1976; Alexander and Borgia 1978; Alexander 1979; Byrne and Whiten 1988). The full implications for human prosocial traits have yet to be developed, although one wide-ranging treatment suggests that social selection may have enormous scope for explaining human capacities for art and literature, as well as capacities for intelligence and cooperation (Alexander 2005).

A closely related model for the evolution of human altruism is based on sexual selection. Geoffrey Miller $(2000 ; 2007)$ has suggested that sexual selection may account for many extreme human cognitive and behavioral traits that are otherwise difficult to explain, especially altruism. He cites evidence that both women and men prefer to marry kind reliable partners, giving a fitness advantage via sexual selection to individuals of both sexes with these heritable personality traits. Sexual selection could thus shape extreme altruism. This potentially important hypothesis has not been emphasized in recent literature, perhaps because it is difficult to study. Miller (2000) acknowledges that other forms of social selection may be important, but mostly, he says, "because they change the social scenery behind sexual selection."

Mate choices create potent selection forces, but so do choices of relationship partners. The fitness benefits from choosing social partners are more distant from direct reproduction, but they can influence fitness nearly every day and at all ages. If partnerships yield a net gain for both parties, then fitness increases with the increase in the number of others who want you as a partner, at least for the first few partners. If partners vary in value, then fitness will be increased by behaving in ways that increase the number of others who want you as a partner (Noë and Hammerstein 1994). A good way to increase the number of available number of partners is to advertise, and to usually provide, more benefits than others can or will provide (Roberts 1998; Barclay and Willer 2007; Hardy and Van Vugt 2006).

Such "competitive altruism" has been the topic of several descriptions and studies (Roberts 1998; Barclay and Willer 2007; Hardy and Van Vugt 2006). The latter two studies are especially germane because they model and provide data that demonstrate competitive altruism in humans. Competitive altruism gives an advantage when extreme generosity results in disproportionate payoffs from pairing with the best partners. In Barclay and Willer's study using a prisoner's-dilemma-like task, generosity levels increased dramatically when participants knew their behaviors were observable and could be used by others choosing partners. The effect was robust even though the experiment was anonymous. Hardy and Van Vugt also demonstrated increased altruism when behavior is observed, and they found that the most altruistic individuals gained the highest status and were preferred as partners, thus gaining benefits.

The resulting positive feedback process can shape costly displays, and preferences for partners who present such displays. Displays of resources, talent and other indicators of partner value are prominent aspects of human cultures (Barkow 1989; Dunbar et al. 1999; Miller 2000; Schaller and Crandall 2003; Alexander 2005). Conspicuous consumption, from potlatches to Rolexes, has been interpreted as wasteful status displays (Veblen 1899), but such displays not only entice mates, they also advertise an individual's desirability as a relationship 
partner or a group member. Competitions in such displays reward only the most extreme and remarkable performances and creations (Veblen 1899; Frank 1999; Alexander 2005).

People advertise their reputations as much as their resources, and displays of moral character are an equally impressive aspect of human cultures (Katz 2000). Reputation display competitions may be important for explaining human moral capacities and altruistic behaviors that are not reliably reciprocated. Recent models suggest that altruism itself may be an honest advertisement based on the handicap principle (Gintis et al. 2001; Pilot 2005; Hardy and Van Vugt 2006; Barclay and Willer 2007).

Strong reciprocity is closely related (Gintis et al. 2001). As Fehr and Henrich put it (2003: 57), "The essential feature of strong reciprocity is a willingness to sacrifice resources in both rewarding fair behavior and punishing unfair behavior, even if this is costly and provides neither present nor future economic rewards for the reciprocator." They argue that this apparently "excess" altruism is not a mistake, but an adaptation that arises because even small amounts of conformist transmission give advantages to cooperate-punish strategies that result in their spread in cultural groups. The previous argument about the Baldwin effect and emergent forces of selection in groups is similar, but focuses more attention on behaviors at the level of the individual. Prior work on the evolution of capacities for commitment (Nesse 2001) is also related, although commitment strategies rely more on intensive communication of threats and promises, and ways to make them believable even when fulfilling the commitment would not be in the actor's interests. As noted already, research on cooperation is vulnerable to confusion because it probably is shaped by multiple selection pressures that are hard to disentangle.

The assortment that brings cooperators together need not be based on recognition or identity tags; simple environmental or partner preferences are sufficient (Pepper and Smuts 2002; Pepper 2007). Any mechanism that associates cooperators gives advantages to those with prosocial traits (Wolf et al. 1999; Frank 2006). The results of such selective association of cooperators can be framed as trait-group selection (Wilson and Sober 1994), but such models are very different from old group selection, so to prevent confusion "an alternative is to state as simply as possible what they are-models of nonrandom assortment of altruistic genes" (West et al. 2007: 11).

The opportunity to choose from a variety of partners, and the possibility of negotiating contracts and prices, suggests applying market models to the problem of cooperation (Noë and Hammerstein 1995; Hammerstein 2001; Noë et al. 2001). Consumers and producers, whether humans, other animals, plants or fungi, select among available partners based upon their utility, availability, and price. Replacement of cheaters with more profitable partners exerts a powerful selection force for transaction quality and the ability to conceal and detect defection (Frank 1988, Trivers 2000). This shapes market efficiency and integrity, even to the apparently maladaptive extreme of guarantees that "the customer is always right." Such guarantees are exploitable and costly, but competition for customers keeps them prevalent.

The argument that social selection shapes extreme traits for winning competitions for relationship partners can be readily expanded to encompass parallel processes at the group level. Individuals in groups assess the qualities of potential future members and admit those who offer the most while demanding the least. Conversely, prospective new members assess which group offers them the most at the least cost. The result is a sorting of individuals by their abilities to contribute resources, creating groups readily ranked in quality. However, because being a big fish in a small pond can payoff better than being a small fish in a big pond, the partner value of members will overlap between groups (Frank 1985).

Skew theory (Reeve and Shen 2006) may clarify the dynamics of individuals competing for resources other than access to reproduction in social groups. Individuals in groups should value new members proportional to their effects on group members' ability to get resources. Potential members display both their resources and their willingness to share them. After an individual joins a group, the dynamics shift to those based on the costs and benefits of allowing a member to stay, and competition for allies and position within a group. Social selection from competitions to join the best groups may be more powerful than competition to be chosen as an individual partner, but the complexities make it wise to focus here on simpler partnerships.

It is important to note that the behaviors of individuals groups can create emergent forces of natural selection in groups that shape otherwise inexplicable traits such as genuine altruism, group loyalty and boundaries that define the in-group and devalue out-groups (Alexander and Borgia 1978; Boyd and Richerson 1985). Such forces may emerge reliably from individuals and partnerships pursing their own interests. While such emergent selection forces would not exist without the group, they are very different from group selection in that they do not depend on the success of the group.

\section{Models}

Most models partition fitness effects into social selection and natural selection components, and describe how covariance between traits in associated partners can account for the strength of social selection (West-Eberhard 1975; West-Eberhard 1983; Tanaka 1996; Wolf et al. 1999; Frank 2006). It is difficult, however, for such models to describe the dynamic process of 


\section{Correlations of G with C: Fixed Partnerships}

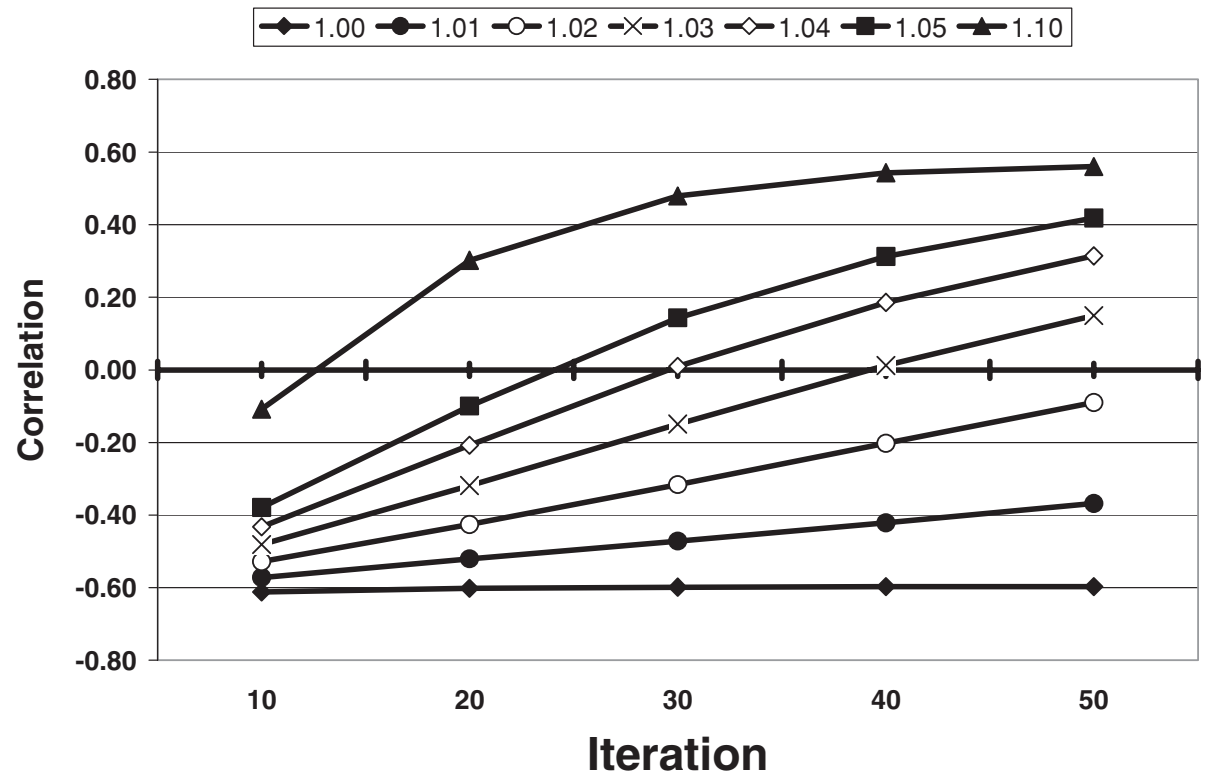

Figure 1.

Correlation of $\mathrm{G}$ with $\mathrm{C}$ for fixed partnerships over 50 iterations for six levels of $\mathrm{R}$.

choosing repeatedly among many possible partners as a function of behaviors that change over time.

An agent-based shared-investment model may help to illustrate some of these processes. A simple initial model assigns each agent a randomly distributed generosity parameter, $\mathrm{G}$, that ranges from 0.0 to 1.0. Each of 100 agents is endowed with capital, $\mathrm{C}=100$. In each iteration, pairs of agents invest a percentage of their total resources, $\left(\mathrm{G}^{*} \mathrm{C}\right)$ and $\left(\mathrm{G}^{\prime *} \mathrm{C}^{\prime}\right)$ respectively (the prime mark indicates the partner's parameters). Both partners receive a payoff equal to half of their total joint investment times $\mathrm{R}$, the rate of return: Payoff $=\mathrm{R}^{*}\left(\left(\mathrm{G}^{*} \mathrm{C}\right)+\left(\mathrm{G}^{\prime *} \mathrm{C}^{\prime}\right)\right) / 2$.

If this model is run without sorting, agents remain in fixed pairs. The agent with a higher $\mathrm{G}$ does worse because it invests more than the partner on each move, but they share the payoffs equally. Despite the higher payoffs for the less generous agent in each pair, when all 100 agents are considered, more generous agents on average have superior payoffs as reflected in increasing correlations of $\mathrm{G}$ with $\mathrm{C}$ with each iteration. The correlation of $\mathrm{G}$ with $\mathrm{C}$ increases with each iteration. How fast it becomes positive depends on R. As shown in Figure 1, when $\mathrm{R}=1.03$, correlations become positive by iteration 40 . For $\mathrm{R}=1.05$ the correlation becomes positive at iteration 25 , but reaches only 0.40 at iteration 50 . When $R=1.10$, the correlation becomes positive at iteration 12 and approaches an asymptote of 0.60 .

Model 2 is the same except that at each iteration the agents are sorted according to $\mathrm{G} \times \mathrm{C}$, the total investment made on the previous move. This increasingly pairs more generous agents as if each one were watching all others and pairing with the available partner who offers the best combination of resources and generosity. More generous agents still accumulate capital more slowly than their less generous partners, but the sorting process greatly increases the maximum correlation and how quickly it becomes positive. As illustrated in Figure 2, $\mathrm{G} \times \mathrm{C}$ becomes positive at the $9^{\text {th }}$ iteration if $\mathrm{R}=1.05$, and at the $5^{\text {th }}$ iteration if $\mathrm{R}=1.10$. Both continue on to correlations much higher than in the model without partner choice.

These simple models illustrate how partner choice can shape increased generosity. The model could easily be elaborated by allowing reproduction as a function of capital accumulation, or by using a genetic algorithm to see what parameters are optimal and whether different subtypes of agents find evolutionarily stable alternative strategies. Such models could also use random normal distributions of $\mathrm{R}$ in order to study the influence of stochastic payoffs. It will be interesting to discover the optimal levels of generosity across different levels of other parameters and whether populations of agents go to a stable equilibrium or if they cycle. Future models also need to incorporate the possibility of deception, although continuing choice among known potential partners makes deception less important than in most reciprocity models. Social selection models lend themselves to investigations of how hierarchy influences cooperation.

\section{The Invisible Hand}

Adam Smith ([1759] 1976) was preoccupied with finding explanations for sympathy, and his followers argue that he would 


\section{Correlations of G with C: Partner Choice}

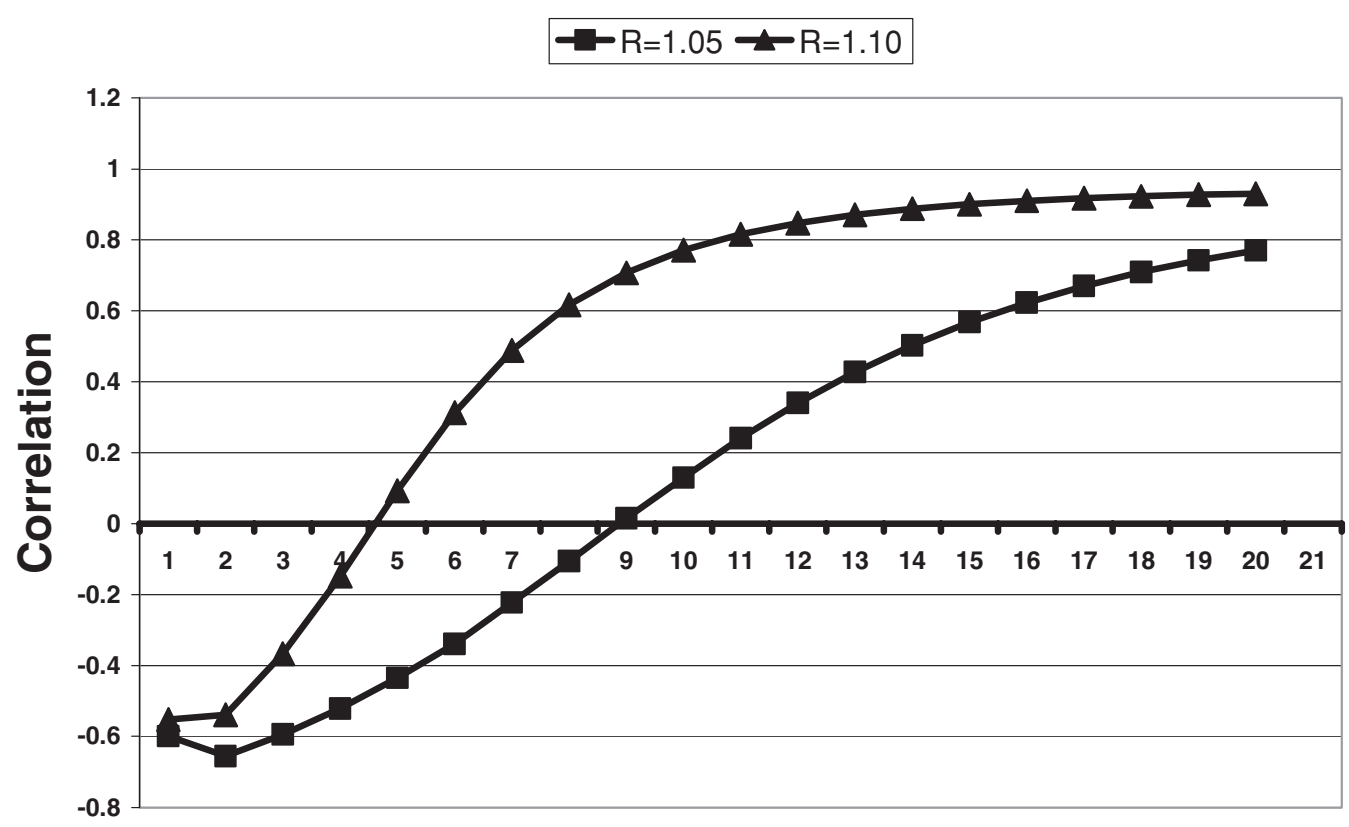

\section{Iteration}

Figure 2.

Correlation of $\mathrm{G}$ with $\mathrm{C}$ given partner choice over 50 iterations for two levels of $\mathrm{R}$.

be dissatisfied with current evolutionary theories of altruism (Khalil 2004). In his book on the moral passions, Smith mentioned the invisible hand only once, and this was with respect to the division of resources. The idea of the invisible hand seems equally germane, however, to the origins of moral emotions. Individuals pursue their interests by trying to attract the best possible partners. To succeed, they must offer to fulfill the wishes and expectations of potential partners at the lowest possible price. This usually requires carrying out many expensive actions that help and please others. Self-interested partner choice may be the invisible hand that shaped human capacities for sympathy.

Social exchange with partner choice gives rise to emergent forces of natural selection that can shape social traits far more sophisticated than generic sympathy. These forces should give fitness advantages to those who pay close attention to what others want, something very much like theory of mind. They could also shape empathic concern for the welfare of partners and strong motives to make reparations, not only for actual defections, but for even hints of possible lack of attention to the other's needs (Wu and Axelrod 1995). And, they can shape love, spite, contempt, and the whole range of social emotions (Nesse 1990). Most globally, these social market forces shape desires to please others in general, and desires to avoid any cause of displeasure. Indeed, powerful internal mechanisms reward us for helping others (Brown et al. 2003), and cause guilt and shame when we cause others pain or disappointment (Gibbard 1990).

\section{Caveats and Conclusions}

Several caveats and limitations should be kept in mind. First, as already noted, multiple mechanisms of selection shape capacities for cooperation. While this article emphasizes the effects of runaway social selection resulting from social partner choice, several other forces are involved, including sexual selection, the benefits of mutualisms, and plain reciprocity.

Second, and closely related, the fitness benefits of social selection are intimately involved with reciprocity and kin selection. In one sense this is not an issue. Other different perspectives, such as reciprocity and kin selection, can be modeled in a common framework. The social selection perspective is distinctive, however, because it shifts the focus of attention away from decisions to cooperate or defect and abilities to detect cheating, and toward the quite different tasks of selecting carefully among a variety of potential partners, trying to discern what they want, and trying to provide it, so one is more likely to be chosen and kept as a partner.

Reciprocity and social selection models of cooperation differ not only because they partition fitness effects differently, but also because social selection gives rise to runaway processes that can account for traits that decrease survival or 
competitiveness, such as extreme altruism. For the same reason, the benefits of socially selected traits may come at the cost of increased vulnerability to serious mental disorders. For instance, rapid selection for complex social capacities may have pushed some traits close to a fitness "cliff-edge" beyond which lies catastrophic cognitive failure of the sort seen in schizophrenia (Nesse 2004).

Social selection calls attention to the locus of selection's action: heritable variations in social traits that influence abilities to get and maintain relationships with preferred social partners. Empathy, self-esteem, guilt, anger, and tendencies to display moral traits and to judge others may be shaped directly by social selection. Instead of describing a stable equilibrium, social selection focuses attention on the dynamic process that shapes social traits.

Third, human nature is not unitary. Some people are profoundly prosocial, others lack all sympathy. Do individuals who lack sympathy have a genetic defect? Or, did they miss some early experience necessary to development of the capacity? Or, is sympathy a facultative trait expressed only in certain social circumstances? Or is selection for such capacities so recent that gene frequencies are changing rapidly? Or are they maintained in some frequency dependent equilibrium? (Mealey 1995). These are important questions, as yet unanswered. While finding the mean values and distributions for any trait in any species is valuable, attempts to essentialize human nature are at odds with both observation of human variation and an evolutionary view of how human nature came to be.

Forces of social selection may also vary significantly between different groups (Henrich et al. 2005). Even within one society, different subgroups show different social patterns. It also seems possible that the benefits of partner choice may be much larger in some settings compared to others. For instance, if most economic activity requires little cooperation and no trading, then attending closely to other's needs will be of little value as compared to a situation in which competitive presentations of self influence fitness strongly. High rates of narcissism may be a reliable product of certain social and economic structures (Lasch 1979).

A related concern is whether the opportunities for partner choice have influenced fitness long enough to create forces of social selection sufficient to shape complex social traits. To find out this will require anthropological data interpreted in this framework. The possibility that capacities for profound sociality arose from culture without influences from natural selection seems unlikely. Humans clearly have social capacities that are qualitatively different from other animals (Kitcher 1993; Dunbar 1998; Tomasello 1999).

Finally, words hide all manner of imprecision that is revealed only by transforming them into mathematical statements. The mathematical models in this paper are rudimentary. Among other factors that need exploration are deception, dif- ferent parameters for payoffs and noise, and the possibility that viscosity or other grouping mechanisms may maintain different equilibria.

No definitive experiment is likely to prove the role of social selection in shaping human capacities for cooperation, and, for the reasons just noted, cross-species comparisons will not be very useful. Nonetheless, just as a reciprocity models suggested looking for specialized cheater detection capacities, social selection models suggest looking for specialized capacities for determining what others want, for monitoring whether one is pleasing them, and for presenting a social self that will make one desirable as a social partner. Of course, we already know quite a lot about theory of mind and the evolution of selfesteem (Leary and Baumeister 2000), so to demonstrate that they were shaped by social selection will require predicting unnoticed aspects and looking to see if they are there.

In sum, partner choice can create runaway forces of social selection that may have shaped human prosocial tendencies and capacities for advanced social cognition that are otherwise difficult to explain. Whether this turns out to be correct awaits additional modeling, experiments, field studies, and further syntheses with the principles of microeconomics.

\section{Acknowledgments}

Thanks for very helpful comments from two anonymous reviewers, and to members of my laboratory group, and to colleagues who offered valuable advice along the way including Robert Axelrod, Lee Dugatkin, Steve Frank, Kern Reeve, Bobbi Low, Richard Nisbett, Peter Railton, Mary Rigdon, Stephen Salant, Stephen Stearns, Barbara Smuts, Mary Jane West-Eberhard, and to Lucy for inspiration.

\section{References}

Alcock J (2001) The Triumph of Sociobiology. New York: Oxford University Press.

Alexander RD (1979) Darwinism and Human Affairs. Seattle: University of Washington Press.

Alexander RD (1987) The Biology of Moral Systems. New York: Aldine de Gruyter.

Alexander RD (2005) Evolutionary selection and the nature of humanity. In: Darwinism and Philosophy (Hösle V, Illies C, eds), 301-348. Notre Dame, IN: University of Notre Dame Press.

Alexander RD, Borgia G (1978) Group selection, altruism, and the levels of organization of life. Annual Review of Ecology and Systematics 9: 449-474.

Amundsen T (2000) Why are female birds ornamented? Trends in Ecology and Evolution 15: 149-155.

Ananth M (2005) Psychological altruism vs. biological altruism: Narrowing the gap with the Baldwin effect. Acta Biotheoretica 53: 217-239.

Andersson M (1994) Sexual Selection. Princeton: Princeton University Press.

Armbruster WS, Antonsen L, Pélabonb C (2005) Phenotypic selection on Dalechampia blossoms: Honest signaling affects pollination success. Ecology 86: 3323-3333.

Axelrod R (1984) The Evolution of Cooperation. New York: Basic Books.

Axelrod R (1986) An evolutionary approach to norms. American Political Science Review 80: 1095-1111. 
Axelrod RM (1997) The Complexity of Cooperation: Agent-based Models of Competition and Collaboration. Princeton: Princeton University Press.

Axelrod RM, Hammond RA, Grafen A (2004) Altruism via kin-selection strategies that rely on arbitrary tags with which they coevolve. Evolution 58: $1833-1838$.

Barkow JH (1989) Darwin, Sex, and Status: Biological Approaches to Mind and Culture. Toronto: University of Toronto Press.

Batson CD (1991) The Altruism Question: Toward a Social Psychological Answer. Hillsdale, NJ: Erlbaum.

Boyd R, Gintis H, Bowles S, Richerson PJ (2003) The evolution of altruistic punishment. Proceedings of the National Academy of Sciences USA 100: 3531-3535.

Boyd R, Richerson PJ (1985) Culture and the Evolutionary Process. Chicago: University of Chicago Press.

Bradbury JW, Vehrencamp SL (1998) Principles of Animal Communication. Sunderland, MA: Sinauer.

Breden F, Wade MJ (1991) "Runaway" social evolution: Reinforcing selection for inbreeding and altruism. Journal of Theoretical Biology 153: 323-337.

Brown SL, Brown RM (2006) Selective investment theory: Recasting the functional significance of close relationships. Psychological Inquiry 17: $1-29$.

Brown SL, Nesse RM, Vinokur AD, Smith DM (2003) Providing social support may be more beneficial than receiving it: Results from a prospective study of mortality. Psychological Science 14: 320-327.

Bull JJ, Rice WR (1991) Distinguishing mechanisms for the evolution of cooperation. Journal of Theoretical Biology 149: 63-74.

Byrne RW, Whiten A (1988) Machiavellian Intelligence: Social Expertise and the Evolution of Intellect in Monkeys, Apes, and Humans. Oxford: Oxford University Press.

Connor RC (1995) Altruism among nonrelatives: Alternatives to the "Prisoner's Dilemma." Trends in Ecology and Evolution 10: 84-86.

Cosmides L (1989) The logic of social exchange: Has natural selection shaped how humans reason? Studies with the Wason selection task. Cognition 31: 187-276.

Crespi BJ (2004) Vicious circles: Positive feedback in major evolutionary and ecological transitions. Trends in Ecology and Evolution 19: 627-633.

Crook JH (1972) Sexual selection, dimorphism, and social organization in the primates. In: Sexual Selection and the Descent of Man (Campbell B, ed), 231-281. Chicago: Aldine.

Darwin C (1871) The Descent of Man and Selection in Relation to Sex. London: John Murray.

Dawkins R (1976) The Selfish Gene. Oxford: Oxford University Press.

de Waal FBM, Macedo S, Ober J, Wright R (2006) Primates and Philosophers: How Morality Evolved. Princeton: Princeton University Press.

Dennett D (1995) Darwin's Dangerous Idea. New York: Simon and Schuster.

Diamond J (2002) Evolution, consequences and future of plant and animal domestication. Nature 418: 700-707.

Dugatkin LA (1997) Cooperation Among Animals: An Evolutionary Perspective. New York: Oxford University Press.

Dugatkin LA (2006) The Altruism Equation: Seven Scientists Search for the Origins of Goodness. Princeton: Princeton University Press.

Dunbar RIM (1996). Grooming, Gossip, and the Evolution of Language. Cambridge, MA, Harvard University Press.

Dunbar RIM (1998) The social brain hypothesis. Evolutionary Anthropology 6: $178-190$.

Dunbar RIM, Knight C, Power C, eds (1999) The Evolution of Culture: An Interdisciplinary View. New Brunswick, NJ: Rutgers University Press.

Fehr E, Fischbacher U (2003) The nature of human altruism. Nature 425: 785-791.

Fehr E, Henrich J (2003) Is strong reciprocity a maladaptation? On the evolutionary foundations of human altruism. In: Genetic and Cultural
Evolution of Cooperation (Hammerstein P, ed.), 55-82. Cambridge, MA: MIT Press.

Fehr E, Rockenbach B (2004) Human altruism: economic, neural, and evolutionary perspectives. Current Opinions in Neurobiology 14: 784-790.

Frank RH (1985) Choosing the Right Pond: Human Behavior and the Quest for Status. New York: Oxford University Press.

Frank RH (1988). Passions within Reason: The Strategic Role of the Emotions. New York: Norton.

Frank RH (1999) Luxury Fever: Why Money Fails to Satisfy in an Era of Excess. New York: Free Press.

Frank SA (1997) The Price equation, Fisher's fundamental theorem, kin selection and causal analysis. Evolution 51: 1712-1729.

Frank SA (1998) Foundations of Social Evolution. Princeton: Princeton University Press.

Frank SA (2006) Social selection. In: Evolutionary Genetics: Concepts and Case Studies (Fox CW, Wolf JB, eds), 350-363. New York: Oxford University Press.

Gibbard A (1990) Wise Choices, Apt Feelings: A Theory of Normative Judgment. Oxford: Oxford University Press.

Gintis H (2000) Strong reciprocity and human sociality. Journal of Theoretical Biology 206: 169-179.

Gintis H, Smith EA, Bowles S (2001) Cooperation and costly signaling. Journal of Theoretical Biology 119: 103-119.

Grafen A (1984) Natural selection, kin selection, and group selection. In: Behavioural Ecology: An Evolutionary Approach (Krebs JR, Davies NB, eds), 62-84. Sunderland, MA: Sinauer.

Grafen A (1990) Biological signals as handicaps. Journal of Theoretical Biology 144: 517-546.

Hamilton WD (1964) The genetical evolution of social behavior, I and II. Journal of Theoretical Biology 7: 1-52.

Hammerstein P (2001) Games and markets: Economic behavior in humans and other animals. In: Economics in Nature: Social Dilemmas, Mate Choice and Biological Markets (Noë R, van Hooff JARAM, Hammerstein P, eds), 1-22. Cambridge: Cambridge University Press.

Hammerstein P, ed (2003) Genetic and Cultural Evolution of Cooperation. Cambridge, MA: MIT Press/ Dahlem University Press.

Henrich J, Boyd R (2001) Why people punish defectors: Weak conformist transmission can stabilize costly enforcement of norms in cooperative dilemmas. Journal of Theoretical Biology 208: 79-89.

Henrich J, Boyd R, Bowles S, Camerer C, Fehr E, Gintis H, McElreath R, Alvard M, Barr A, Ensminger J, Henrich NS, Hill K, Gil-White F, Gurven M, Marlowe FW, Patton JQ, Tracer D (2005) "Economic man" in crosscultural perspective: Behavioral experiments in 15 small-scale societies. Behavioral and Brain Sciences 28: 795-815.

Henrich J, McElreath R, Barr A, Ensminger J, Barrett C, Bolyanatz A, Cardenas JC, Gurven M, Gwako E, Henrich N, Lesorogol C, Marlowe F, Tracer D, Ziker J (2006) Costly punishment across human societies. Science 312: 1767-1770.

Hirshleifer J (1999) There are many evolutionary pathways to cooperation. Journal of Bioeconomics 1: 73-93.

Humphrey N (1997) Varieties of altruism—and the common ground between them. Social Research 64: 199-209.

Humphrey NK (1976) The social function of intellect. In: Growing Points in Ethology (Bateson PG, Hinde RA, eds), 303-318. London: Cambridge University Press.

Khalil EL (2004) What is altruism? Journal of Economic Psychology 25: 97-123.

Katz L (2000) Evolutionary Origins of Morality: Cross-Disciplinary Perspectives. Devon: Imprint Academic.

Kitcher P (1993) The evolution of human altruism. Journal of Philosophy 90: 497-516. 
Kokko H, Brooks R, Jennions MD, Morley J (2003) The evolution of mate choice and mating biases. Proceedings of the Royal Society B270: 653664.

Kokko H, Jennions MD, Brooks R (2006) Unifying and testing models of sexual selection. Annual review of Ecology and Evolutionary Systematics 37: 43-66.

Krebs DL (2000) The evolution of moral dispositions in the human species. Annals of the New York Academy of Sciences 907: 132-148.

Krebs J, Dawkins R (1984) Animal signals: Mind-reading and manipulation. In: Behavioral Ecology: An Evolutionary Approach (Krebs JR, Davies NB, eds), 380-402. Sunderland, MA: Sinauer.

Kummel M, Salant SW (2006) The economics of mutualisms: Optimal utilization of mycorrhizal mutualistic partners by plants. Ecology 87: 892902.

Laland KN, Odling-Smee J, Feldman MW (2000) Niche construction, biological evolution, and cultural change. Behavioral and Brain Sciences 23: 131-175.

Lande R, Arnold SJ (1983) The measurement of selection on correlated characters. Evolution 37: 1210-1226.

Lasch C (1979) The Culture of Narcissism: American Life in an Age of Diminishing Expectations. New York: Warner Books.

Leach HM (2003) Human domestication reconsidered. Current Anthropology 44: 349-368.

Leary MR, Baumeister RF (2000) The nature and function of self-esteem: Sociometer theory. In: Advances in Experimental Social Psychology (Zanna MP, ed), vol. 32: 2-51. San Diego: Academic Press.

Lehmann L, Keller L (2006) The evolution of cooperation and altruism: A general framework and a classification of models. Journal of Evolutionary Biology 19: 1365-1376.

Manson JH, Navarrete CD, Silk JB, Perry S (2004) Time-matched grooming in female primates: New analyses from two species. Animal Behavior 67: 493-500.

Mealey L (1995) Sociopathy. Behavioral and Brain Sciences 18: 523-599.

Midgley M (1994) The Ethical Primate: Humans, Freedom, and Morality. New York: Routledge.

Miller G (2007) Sexual selection for moral virtues. Quarterly Review of Biology 82: 97-126.

Miller GF (2000) The Mating Mind: How Sexual Choice Shaped the Evolution of Human Nature. New York: Doubleday.

Mills J, Clark MS (1994) Communal and exchange relationships: Controversies and research. In: Theoretical Frameworks for Personal Relationships (Erber R, Gilmour R, eds), 29-42. Hillsdale, NJ, Erlbaum.

Nesse RM (1990) Evolutionary explanations of emotions. Human Nature 1: 261-289.

Nesse RM (2001) Evolution and the Capacity for Commitment. New York: Russell Sage Foundation

Nesse RM (2004) Cliff-edged fitness functions and the persistence of schizophrenia (commentary). Behavioral and Brain Sciences 27: 862-863.

Nesse RM (2006) Why so many people with selfish genes are pretty niceExcept for their hatred of The Selfish Gene. In: Richard Dawkins (Grafen A, Ridley M, eds), 203-212. London: Oxford University Press.

Noë R (2001) Biological markets: Partner choice as the driving force behind the evolution of mutualisms. In: Economics in Nature: Social Dilemmas, Mate Choice and Biological Markets (Noë R, van Hooff JARAM, Hammerstein P, eds), 93-118. New York: Cambridge University Press.

Noë R, Hammerstein P (1994) Biological markets: Supply and demand determine the effect of partner choice in cooperation, mutualism and mating. Behavioral Ecology and Sociobiology 35: 1-11.

Noë R, Hammerstein P (1995) Biological markets. Trends in Ecology and Evolution 10: 336-339.
Noë R, van Hooff JARAM, Hammerstein P, eds (2001) Economics in Nature: Social Dilemmas, Mate Choice and Biological Markets. New York: Cambridge University Press.

Nowak MA (2006) Five rules for the evolution of cooperation. Science 314: $1560-1563$.

Nowak MA, Sigmund K (1998) Evolution of indirect reciprocity by image scoring. Nature 393: 573-577.

Pepper JW (2007) Simple models of assortment through environmental feedback. Artificial Life 13: 1-9.

Pepper JW, Smuts BB (2002) A mechanism for the evolution of altruism among nonkin: Positive assortment through environmental feedback. American Naturalist 160: 205-213.

Pilot M (2005) Altruism as advertisement: A model of the evolution of cooperation based on Zahavi's handicap principle. Ethology, Ecology and Evolution 17: 217-231.

Price EO (1984) Behavioral aspects of animal domestication. Quarterly Review of Biology 59: 1-32.

Queller DC (1992) A general model for kin selection. Evolution 46: 376-380.

Queller DC, Ponte E, Bozzaro S, Strassmann JE (2003) Single-gene greenbeard effects in the social amoeba Dictyostelium discoideum. Science 299: 105-106.

Queller DC, Strassmann JE (1998) Kin selection and social insects. BioScience 48: 165-175

Ridley M (1997) The Origins of Virtue: Human Instincts and the Evolution of Cooperation. New York: Viking.

Riolo RL, Cohen MD, Axelrod R (2001) Evolution of cooperation without reciprocity. Nature 414: 441-443.

Roberts G (1998) Competitive altruism: From reciprocity to the handicap principle. Proceedings of the Royal Society B265: 427-431.

Rothstein SI (1980) Reciprocal altruism and kin selection are not clearly separable phenomena. Journal of Theoretical Biology 87: 255-261.

Roughgarden J, Oishi M, Akcay E (2006) Reproductive social behavior: Cooperative games to replace sexual selection. Science 311: 965969.

Sachs JL, Mueller UG, Wilcox TP, Bull JJ (2004) The evolution of cooperation. Quarterly Review of Biology 79: 135-160.

Schaller M, Crandall CS, eds (2003) The Psychological Foundations of Culture. Mahwah, NJ: Erlbaum.

Segerstråle UCO (2000) Defenders of the Truth: The Battle for Science in the Sociobiology Debate and Beyond. New York: Oxford University Press.

Sigmund K (1993) Games of Life: Explorations in Ecology, Evolution, and Behaviour. New York: Oxford University Press.

Silk JB (2003) Cooperation without counting: The puzzle of friendship. In: Genetic and Cultural Evolution of Cooperation (Hammerstein P, ed), 39-54. Cambridge, MA: MIT Press.

Simms EL, Taylor DL (2002) Partner choice in nitrogen-fixation mutualisms of legumes and rhizobia. Integrative and Comparative Biology 42: 369 380.

Simon HA (1990) A mechanism for social selection and successful altruism. Science 250: 1665-1668.

Smith A (1976) The Theory of Moral Sentiments. Oxford: Clarendon Press. Orig. 1759

Smuts BB (1985) Sex and Friendship in Baboons. New York: Aldine.

Stevens JR, Cushman FA, Hauser MD (2005) Evolving the psychological mechanisms for cooperation. Annual Review of Ecology, Evolution, and Systematics 36: 499-518.

Tanaka Y (1996) Social selection and the evolution of animal signals. Evolution 50: 512-523.

Tibbetts EA (2004) Complex social behaviour can select for variability in visual features: A case study in Polistes wasps. Proceedings of the Royal Society B271: 1955-1960. 
Tomasello M (1999) The Cultural Origins of Human Cognition. Cambridge, MA: Harvard University Press.

Tooby J, Cosmides L (1996) Friendship and the Banker's Paradox: Other Pathways to the Evolution of Adaptations for Altruism. In: Evolution of Social Behaviour Patterns in Primates and Man (Smith JM, Runciman WG, Dunbar RIM, eds), 119-143. London: British Academy/Oxford University Press.

Trivers RL (1971) The evolution of reciprocal altruism. Quarterly Review of Biology 46: 35-57.

Trivers RL (1985) Social Evolution. Menlo Park: California, Benjamin/ Cummings.

Trivers R (2000) The elements of a scientific theory of self-deception. Annals of the New York Academy of Sciences 907: 114-131.

Veblen T (1899) The Theory of the Leisure Class: An Economic Study in the Evolution of Institutions. New York: Macmillan.

Weber BH, Depew DJ, eds (2003) Evolution and Learning: The Baldwin Effect Reconsidered. Cambridge, MA: MIT Press.

Wedekind C, Milinski M (2000) Cooperation through image scoring in humans. Science 288: 850-852.

West-Eberhard MJ (1975) The evolution of social behavior by kin selection. Quarterly Review of Biology 50: 1-33.

West-Eberhard MJ (1979) Sexual selection, social competition, and evolution. Proceedings of the American Philosophical Society 123: 222-234.

West-Eberhard MJ (1983) Sexual selection, social competition, and speciation. Quarterly Review of Biology 58: 155-183.
West-Eberhard MJ (2003) Developmental Plasticity and Evolution. New York: Oxford University Press.

West SA, Griffin AS, Gardner A (2007) Social semantics: Altruism, cooperation, mutualism, strong reciprocity and group selection. Journal of Evolutionary Biology 20: 415-432.

West SA, Pen I, Griffin AS (2002) Cooperation and competition between relatives. Science 296: 72-75.

Wilkinson GS (1984) Reciprocal food sharing in the vampire bat. Nature 308: 181-184.

Williams GC (1966) Adaptation and Natural Selection: A Critique of Some Current Evolutionary Thought. Princeton: Princeton University Press.

Wilson DS, Sober E (1994) Reintroducing group selection to the human behavioral sciences. Behavioral and Brain Sciences 17: 585607.

Wilson EO (1975) Sociobiology. Cambridge, MA: Harvard University Press.

Wolf JB, Brodie ED III, Moore AJ (1999) Interacting phenotypes and the evolutionary process. II. Selection resulting from social interactions. American Naturalist 153: 254-266.

Wright R (1994) The Moral Animal: The New Science of Evolutionary Psychology. New York: Pantheon Books.

Wynne-Edwards VC (1962) Animal Dispersion in Relation to Social Behavior. Edinburgh: Oliver and Boyd.

Wu J, Axelrod R (1995) How to cope with noise in the iterated prisoner's dilemma. Journal of Conflict Resolution 39: 183-189. 